\title{
Physics in daily life as a booklet
}

ๆ

le hy is water blue? How do we localize sound? Why do we sing in the bath? Why is ice so slippery? What is the speed of falling raindrops?

Finally the "Physics in Daily Life" columns which appeared in Europhysics News over the years are brought together in one inspiring volume!

It provides answers to everyday questions like those above, and it explains the wonders of a candle flame, the physics of the sauna, and the mysteries of bubbles and balloons.

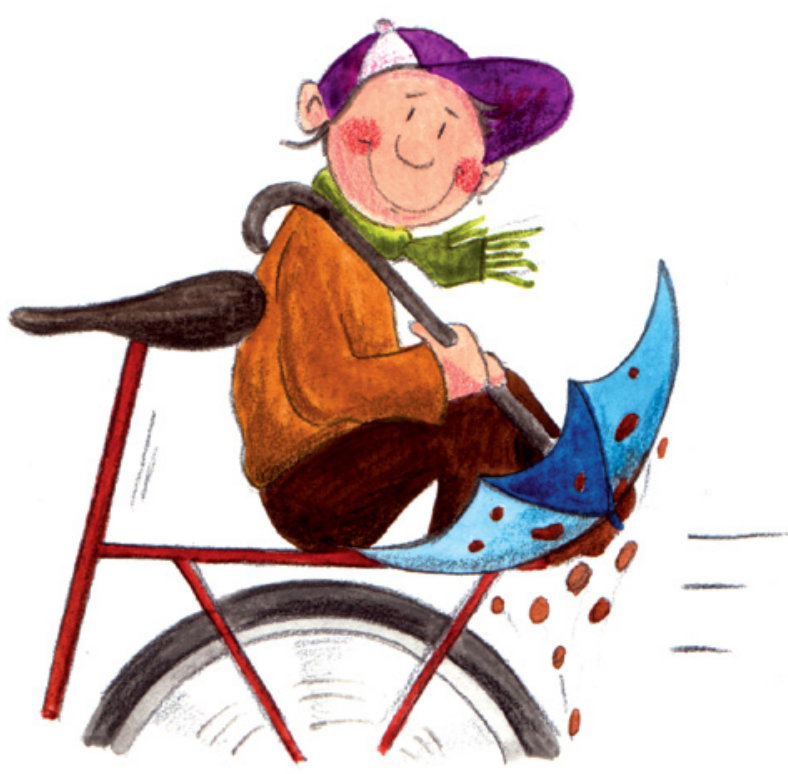

THE MUDGUARD

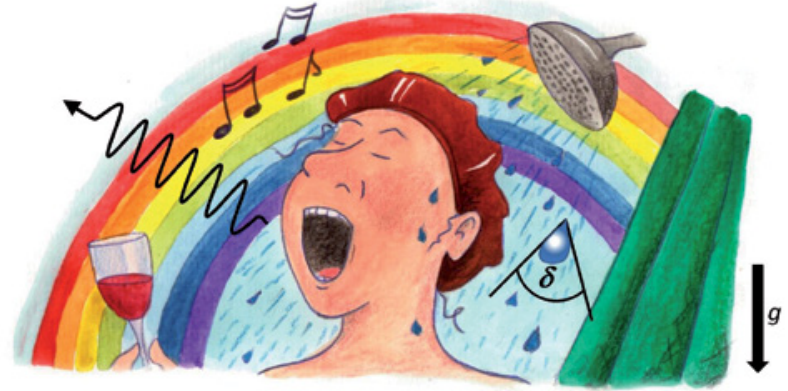

Written by Jo Hermans and illustrated by Wiebke Drenckhan, this book represents science at its most accessible and satisfying. To quote Sir Arnold Wolfendale (Past-President of the EPS) in his foreword: "The present volume is a feast of erudition and humour, by way of the excellent accompanying cartoons as well as the subject matter".

This booklet is the ideal present for your colleagues, for your students and for yourself.

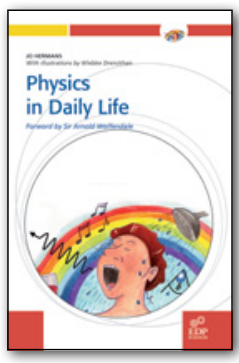

$18 €$ - ISBN : 978-2-7598-0705-5 To order:

http://www.edition-sciences.com/ physics-in-daily-life.htm

If you want to order more than 10 copies, a discount can be arranged. Please contact:

agnes.henri@edpsciences.org

\section{THE 'PHYSICS IN DAILY LIFE' PAGE WIDENS ITS SCOPE}

Many of you have appreciated the 'Physics in daily life' page for more than six years. In response to the suggestions of several readers, the 40 items which appeared thus far have been collected in a booklet (see elsewhere on this page).
We now wish to open the door to a column with a wider scope, covering opinions and - possibly controversial - letters from our readers. Our goal is to have such a column in each issue along with the traditional 'Physics in daily life' column, hoping that our talented cartoonist will be inspired to produce an appropriate illustration each time. Her talents are exemplified also on this page (illustrations taken from the 'Physics in daily life' book). 